American Journal of Pharmaceutical Education 2021; 85 (1) Article 8414.

\title{
COMMENTARY
}

\section{Ten Tips for Pharmacy Faculty Members for Successfully Navigating Promotion and Tenure}

\author{
Velliyur Viswesh, PharmD, ${ }^{\mathrm{a}}$ Karen Hassell, PhD, MA, ${ }^{\mathrm{b}}$ Leanne Coyne, $\mathrm{PhD},{ }^{\mathrm{c}}$ Brian L. Erstad, PharmD ${ }^{\mathrm{d}}$

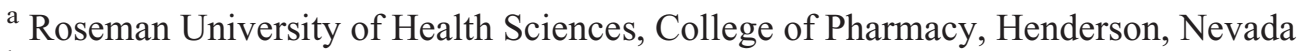 \\ ${ }^{\mathrm{b}}$ West Coast University, School of Pharmacy, Los Angeles, California \\ ${ }^{c}$ California Health Sciences University, College of Osteopathic Medicine, Clovis, California \\ ${ }^{\mathrm{d}}$ University of Arizona, College of Pharmacy, Tucson, Arizona
}

Submitted October 2, 2020; accepted November 23, 2020; published January 2021.

\begin{abstract}
This paper presents 10 key tips or recommendations for successful navigation of the promotion and tenure process. The 10 key tips are: know institutional expectations, develop an action plan at least two to three years in advance; identify your balance of teaching, scholarship, service; synergize activities and develop a niche; prioritize time to activities of high-impact to promotion and tenure; track achievements in the format expected for promotion and tenure application; seek out faculty guidance on promotion and tenure; meet with mentor(s) regularly to review progress; have a well-written personal statement; and have your final dossier reviewed by colleagues. Faculty members are more likely to be successful through timely and appropriate planning, balancing and synergizing activities, tracking activities and achievements, developing a well-written personal statement, and requesting help from experienced colleagues.
\end{abstract}

Keywords: academic, successful, teaching, promotion, tenure

\section{INTRODUCTION}

Promotion, tenure, or both are common expectations for full-time faculty members at academic institutions, including at colleges and schools of pharmacy. Both promotion and tenure applications require faculty to prepare a detailed dossier describing their professional and academic accomplishments over a defined period. This dossier undergoes review by internal committees and often reviewers external to the institution to determine merit. Faculty may also apply for promotion and tenure simultaneously if their institution permits. A key difference between promotion and tenure tracks is that the tenure-track system in colloquial terms is an "up or out" system. In other words, tenuretrack faculty members are required to apply for tenure within a pre-specified timeline and failure to achieve tenure typically results in termination of appointment. Promotion on the other hand is not typically contractually obligated, although most administrators expect their faculty to apply for promotion. As such, expectations of faculty applying for tenure vary from those of faculty applying for promotion. This difference in expectations for tenure-track vs non-tenure-track faculty with respect to contractual obligations is reflected in expectations for scholarship and

Corresponding Author: Brian L. Erstad, University of

Arizona, 1295 N. Martin Ave., Tucson, AZ 85721. Tel: 520626-4289. Email: erstad@pharmacy.arizona.edu clinical practice (for clinical faculty). For example, one survey found that tenure-track faculty were expected to produce more grants per year and more peer-reviewed publications per year than non-tenure-track faculty. This additional expectation of scholarship was offset by a decreased percentage of effort toward clinical practice but service requirements were similar. ${ }^{1}$ It is therefore important for faculty to understand these differences and expectations at their institutions, particularly at the point of committing to a tenure- or non-tenure-track appointment. Ultimately, the process of applying for either promotion or tenure has significant overlap and similarities. The purpose of this commentary is to summarize 10 key tips or recommendations for successful navigation of the promotion and tenure process based on a presentation of this topic given at the AACP Annual Meeting Pharmacy Education 2020. The authors did not attempt to rank the 10 tips in any order of importance or chronology, but rather the numbering was used simply to delineate the tips.

\section{DISCUSSION}

Tip One: Understand the Promotion and Tenure Criteria and Expectations at Your Institution

Expectations for promotion and tenure can vary from one institution to the next. As such, it is imperative for all faculty to familiarize themselves with their institution-specific 


\section{American Journal of Pharmaceutical Education 2021; 85 (1) Article 8414.}

promotion and tenure criteria. In a survey of 225 pharmacy faculty and administrators, only $66 \%$ agreed that their institution provided clear and objective criteria for tenure. ${ }^{2}$ The other one-third either disagreed or were unsure, indicating that lack of understanding of promotion and tenure criteria is common. Interestingly, there were differences in the perceived level of understanding between respondents from private and public institutions. For example, the recognition of the importance of scholarship was common to respondents from private and public institutions, but there was a greater recognition of the importance of service and teaching by respondents from private institutions. In another survey of 197 pharmacy faculty, scholarship was perceived to be the most important criteria for promotion and tenure. ${ }^{3}$ Of 29 criteria in their survey, five out of the top six ranked by importance pertained to scholarship, including peerreviewed publications, funding, invited presentations of research, and other scholarly writing such as book chapters. Of note, this survey population was comprised of $57 \%$ tenure-track faculty and only $37 \%$ pharmacy practice faculty, which likely contributed to a higher emphasis on scholarship.

\section{Tip Two: Develop an Action Plan at Least Two to Three Years Prior to P\&T Application}

Ideally, discussions about promotion and tenure with the department head (or other immediate supervisor) should occur prior to hire as these discussions will serve as a basis for your action plan. ${ }^{4}$ If these discussions did not take place during the hiring phase, they should be done as soon as possible after starting your position so you have an action plan that you can implement at least 2-3 years prior to being reviewed for promotion and tenure. The first step in creating an action plan is to have a clear understanding of the expectations for your position and for a successful promotion and tenure review. ${ }^{5}$ You need this information in order to complete the second step of your action plan, which is a listing of the undertakings needed to achieve a successful promotion and tenure review. In addition to your department head or immediate supervisor, talk to senior faculty about their views concerning successful promotion and tenure. In your discussions about promotion and tenure, the responses to several questions are likely to affect your action plan. What is the process for promotion and tenure and expectations for a successful promotion and tenure review? Process issues relate to the promotion clock and schedule, promotion policies and criteria, formatting of dossier, administrator and committee reviews, and, if applicable, promotion delay requests or appeals. Questions related to expectations for a successful review include common problems with promotion and tenure dossiers, how summative (eg, yearly) evaluations mesh with expectations for promotion and tenure, and what criteria (eg, publications in highimpact journals, abstracted presentations at national meetings, research funding, teaching or service awards) seem to be of particular high value in the decisionmaking process. The initial breakdown of your effort for teaching, scholarship, and service, and possible changes in your percent effort over time, are issues of overarching and vital importance to the discussion of promotion and tenure. All of the information garnered from these discussions will allow you to translate the promotion and tenure criteria into tasks (step 2) and timelines for completion (step 3). Step 4 is assessing any resources you need to complete your plan. For example, you may need funding to present the results of your research at professional meetings, which may require discussions with your department head or supervisor if you did not receive some form of start-up funding. Step 5 of the process is having periodic assessments of your progress toward dossier submission.

Tip Three: Balance Teaching, Scholarship, and Service Relative to Promotion and Tenure Expectations

Presuming the breakdown of your percent effort for teaching, scholarship, and service were discussed before or soon after hire, you will want to discuss the evaluation process for each of these areas with your department head on a yearly basis, and for promotion and tenure. Didactic teaching efforts may be assessed by a variety of methods, including student evaluations, peer evaluations, or evaluations by instructional design specialists. Didactic core teaching responsibilities are virtually always evaluated, but what about teaching in laboratory or discussion sessions, elective coursework, student assessment activities, such as patient simulations or objective structured clinical examinations, interprofessional teaching, or teaching outside of your college or school, such as experiential teaching for clinical faculty? Additionally, are activities such as serving as an advisor for a student organization or overseeing students in community service activities forms of teaching or service? Similarly, what is the definition and categories of research or scholarship for annual evaluations and promotion and tenure? Does your department, college, and university have a broader and more inclusive view of scholarship that includes activities such as educational research, or a more restrictive view of research such as experiments in a laboratory ${ }^{6-8}$ For the last category of service, how is service, including clinical service, taken into account for ongoing evaluations and promotion and tenure? For example, are all forms of departmental, college, and university service, such as 


\section{American Journal of Pharmaceutical Education 2021; 85 (1) Article 8414.}

administrative responsibilities, committee or task force efforts, mentoring and advising students, serving as a faculty liaison for student-related activities, or various forms of external service, such as involvement in professional organizations or associations, taken into account?

\section{Tip Four: Synergize Teaching, Scholarship, and Service and Develop a Niche/Focus in Each}

While some colleges and schools may not require a niche or focus for a faculty member to go from assistant to associate professor, virtually all faculty eventually must narrow the focus of their teaching, scholarship, and external service activities, so it is never too early to start synergizing your activities in these areas. When you consider synergizing your activities, you need to think a priori about how you can integrate teaching, scholarship, and service, including clinical service if applicable. Additionally, you should consider volunteering for efforts that will help develop your integration and scholarship skills, such as serving as a reviewer for a scholarly journal, serving on grant review committees, serving on editorial boards, and working on projects with more established researchers. ${ }^{9}$ It is common for newer faculty to think about scholarship after teaching or service activities have taken place, but ideally, you should be thinking about potential scholarship opportunities whenever you are assigned or considering new teaching or service responsibilities. Assuming your institution does have a more inclusive view of scholarship, you can start by learning more about methodologies for educational research that are more likely to lead to dissemination through activities, such as formal presentations and peer-reviewed publications. ${ }^{10-11}$ Faculty colleagues who agree to serve as peer reviewers of your teaching may have suggestions for converting your didactic teaching efforts into a form of scholarship. ${ }^{12}$ Clinical faculty should bring their wealth of information about clinical practice into the classroom setting. Students are much more likely to pay attention to the information being taught when they can see the direct relevance of the information to patient care. Similarly, the practice setting is fertile ground for various forms of clinical scholarship.

\section{Tip Five: Prioritize and Balance Your Time Toward Actions Most Influential to P\&T}

To balance your time effectively, it is important to identify your institution's expectations for faculty promotion and tenure as expectations may differ depending on a faculty member's track and disciplinary focus. ${ }^{13,14}$ In addition, faculty at new pharmacy schools may face some unique challenges associated with managing teaching, research, and scholarship, while also developing new curriculum. In most public institutions, research and scholarship is likely to have at least a moderate influence on successful promotion and tenure, while service may be undervalued. ${ }^{15}$ This emphasizes the importance of prioritizing time for research even with obligations that draw your attention to other tasks. Lack of confidence in research and scholarship skills is commonplace in academic pharmacy because most faculty received limited training in this area while a pharmacy student. This can tempt faculty to procrastinate about research and scholarship projects in favor of focusing on more familiar activities. ${ }^{16}$ Methods to increase confidence include asking experienced colleagues for guidance, working with colleagues on their research projects, and starting with small research projects. It can be challenging to find time for research when so many other academic responsibilities demand your attention. External and internal pressure may encourage you to focus on shorter term projects that yield faster results. ${ }^{17}$ You may just be overwhelmed from having too many responsibilities. Consider strategies to ensure that you are able to give sufficient attention to research and scholarship, including requesting protected time to dedicate toward research. Correspondence can absorb a significant amount of time, so it may be helpful to set aside time for emails each day and "disconnect" outside of these times. Avoid excessive committee work if possible. The average commitment for faculty is serving on one college committee and one university committee. ${ }^{18}$

\section{Tip Six: Track Achievements in Detail in the Format Required for Promotion and Tenure Application}

Tracking achievements can be one of the easiest parts of the promotion and tenure process or one of the most tedious depending on how you organize your supporting evidence. The first step is to determine if your institution uses an electronic platform to help you manage your promotion and tenure application. If this is the case, that platform can serve as a repository of information and will help you to organize your documents. If not, a simple file structure containing folders for each section of your document will help. It is advisable to use a cloud-based platform if possible, as this will ensure your files are secure and safe from accidental deletion. Cloud-based platforms also maintain document history, so you can go back to previous versions if the need arises. If a cloudbased platform is not an option, consider frequently backing up your files on multiple devices. Regardless of the system you use, the best way to track achievements in detail is to set up a file system early and update it often.

Tip Seven: Seek Out Faculty Guidance on Promotion and Tenure and Look at Examples of Dossiers

The promotion and tenure process is challenging, but there are opportunities to seek help throughout the 


\section{American Journal of Pharmaceutical Education 2021; 85 (1) Article 8414.}

process, such as asking more senior faculty to share their dossiers with you (see Tip Ten). Workshops are another excellent source of information that can boost confidence and provide numerous tips and tricks. Internal workshops, whether hosted by your department, college, or university, can be an excellent source of information on institution-specific requirements. This is particularly true when the host of the workshop is someone who has successfully made it through the process at your institution. Seek external workshops offered by organizations, at annual meetings, and even at other institutions. Take advantage of these opportunities when you can. External workshops may provide you with an excellent opportunity to meet potential dossier reviewers or mentors who can provide support. Evidence has shown that faculty development increases faculty engagement and productivity, which is beneficial regardless of whether it enhances success in promotion and tenure. ${ }^{19}$

\section{Tip Eight: Identify One or More Mentors and Meet with Them Regularly}

Effective mentorship is a vital component for achieving promotion and tenure, and identifying mentor(s) early in the process is important as you develop and implement your action plan. Experienced mentors who have successfully navigated the promotion and tenure process can guide you by discussing their failures as well as successes. A mentor can not only be a role model and give advice on the steps of your action plan, but also serve as a source of encouragement, motivation, and support. Finding the right mentor is important as the nature of the relationship must be one of mutual respect and must be the right fit for both mentee and mentor. Work with your department chair or other supervisor to identify at least one mentor who is able to meet with you on a regular basis and allot time for discussion. Mentors can help you identify gaps in your portfolio and suggest strategies on how to address them. Also, try to meet with a member of your department or college promotion and tenure committee as they are likely to have insight and suggestions with respect to the dossier and the promotion and tenure process. In some cases, you may need to seek mentoring outside your own institution. In one survey involving 225 pharmacy faculty and administrators, $65 \%$ of administrators believed that their institution provided sufficient mentoring for promotion and tenure, while only $38 \%$ of faculty felt this way. ${ }^{20}$ However, $63 \%$ of all respondents agreed that there was a need for tenure reform.

Tip Nine: Ensure Your Personal Statement Emphasizes Your Achievements and Explains Gaps

The importance of the personal statement associated with most promotion and tenure dossiers is often under- appreciated by less experienced faculty who are more familiar with quantifying information on their curricula vitae. The personal statement is much more of a qualitative expression of the significance (ie, how you have made a difference) and impact of your achievements. Your statement will have quantitative aspects, but it should not just be a repetition of information contained in your curriculum vitae. For example, you should include information that serves to benchmark your achievements relative to internal and external peers based on your breakdown of effort with respect to teaching, scholarship, and service. You will want to draw on evidence to support your statements, such as student and peer evaluations of teaching, journal impact factors, or author-level metrics (eg, h-index) for scholarship, and other material that is supportive of the impact of your service efforts (eg, for all faculty, evidence of successful working relationships, committee work, awards or recognitions, and for clinical faculty, metrics related to patient care activities, development of protocols or guidelines, development of practice agreements, preceptorship, program development, practice site educational activities). There needs to be a balance struck between being too modest and overstating your accomplishments. Recognize that with the exception of external reviewers, others involved in the review process are not likely to understand jargon specific to your field, so write the personal statement in a manner appropriate for a non-specialist audience.

\section{Tip Ten: Seek Feedback and Have Your Dossier Reviewed by Senior Colleagues}

You want to get as much feedback as possible from a variety of sources, including senior colleagues outside of your own institution. Because it is common for junior faculty members to have a single mentor, it is important to seek additional constructive criticism throughout the process from senior colleagues who are well versed in the promotion and tenure process and can help to make sure your dossier complies with all of the formatting requirements of your institution. Seek feedback from a range of faculty both familiar and unfamiliar with your areas of teaching, scholarship, and service in order to get a variety of perspectives. Ask colleagues who have successfully navigated the promotion and tenure process to share their dossiers with you. Ideally, these dossiers would be from someone in your own department who has a breakdown of effort and expectations that is similar to yours. However, examples of dossiers of other faculty will give you additional perspectives on expectations. If your institution requires external reviewers as part of the evaluation process, you should discuss with your chair about how reviewers are selected to make sure they are as close to 


\section{American Journal of Pharmaceutical Education 2021; 85 (1) Article 8414.}

your field and breakdown of effort as possible. Finally, if there is no mandated deadline for promotion, as is common for non-tenure-track faculty, it is better to delay your application rather than trying to force it though the process if your mentors and senior colleagues are telling you that your dossier needs more work.

\section{SUMMARY}

Despite its ubiquitous nature in academia, there are limited publications providing guidance for pharmacy faculty regarding the promotion and tenure process. In addition, expectations for promotion and tenure may vary across institutions. Faculty members are more likely to be successful by having a clear understanding of promotion and tenure criteria and expectations for successful review in conjunction with timely and appropriate action planning, balancing responsibilities, synergizing activities, prioritizing and balancing time, tracking activities and achievements, seeking development activities, identifying mentors, developing a well-written personal statement, and requesting help from experienced colleagues.

\section{REFERENCES}

1. Marcinak RR, Vuernick EL, Schmidt KL et al. Go up or get out?! Promotion and tenure policies in pharmacy practice. Abstracts of the $117^{\text {th }}$ annual meeting of the AACP, Anaheim, CA. Am J Pharm Educ. 2016;80(5):S2

2. Pfeiffenberger JA, Rhoney DH, Cutler SJ, et al. Perceptions of tenure and tenure reform in academic pharmacy. Am J Pharm Educ. 2014;78(4):75.

3. Wolfgang AP, Gupchup GV, Plake KS. Relative importance of performance criteria in promotion and tenure decisions: perceptions of pharmacy faculty members. Am J Pharm Educ. 1995;59(4):342-7. 4. Erstad BL. Surviving and Thriving in the Academic Setting. In: Zlatic TD, ed. Clinical Faculty Survival Guide. American College of Clinical Pharmacy, Lenexa, KS 2010:21-36.

5. Kennedy DR, Calinski DM. P\&T and me. Am J Pharm Educ. 2018;82:Article 7048.

6. Popovich NG, Abel SR. The need for a broadened definition of faculty scholarship and creativity. Am J Pharm Educ. 2002;66:59-65.
7. Brazeau GA. Revisiting faculty service roles - is "faculty service" a victim of the middle child syndrome? Am J Pharm Educ. 2003;67: Article 85.

8. Smesny AL, Williams JS, Brazeau GA, Weber RJ, Matthews HW, Das SK. Barriers to scholarship in dentistry, medicine, nursing, and pharmacy practice faculty. Am J Pharm Educ. 2007;71:Article 91. 9. Ensom MHH. Research and Scholarship for Researcher-Educator Faculty: Top 10 Survival Tips. In: Clinical Faculty Survival Guide. TD Zlatic . (ed); Lenexa, KS: American College of Clinical Pharmacy (ACCP), 2010:259-267

10. McLaughlin JE, Dean MJ, Mumper RJ, Blouin RA, Roth MT. A roadmap for educational research in pharmacy. Am J Pharm Educ. 2013;77:Article 218.

11. DiPiro JT. Good teaching is good science. Am J Pharm Educ. 2007;71:Article 10.

12. Schultz KK, Latif D. The planning and implementation of a faculty peer review teaching project. Am J Pharm Educ. 2006;70: Article 32.

13. Behar-Horenstein LS, Beck DE, Su Y. Perceptions of pharmacy faculty need for development in educational research. Curr Pharm

Teach Learn. 2018;10(1):34-40.

14. Whitman ME, Hendrickson AR, Townsend AM. Research commentary. academic rewards for teaching, research, and service: data and discourse. Inform Syst Res. 1999;10(2):99-109. doi:10.1287/ isre.10.2.99

15. Guglielmo BJ, Edwards DJ, Franks AS, et al. A critical appraisal of and recommendations for faculty development. Am J Pharm Educ. 2011;75(6):122. doi:10.5688/ajpe756122

16. Kehrer JP, Svensson CK. Advancing pharmacist scholarship and research within academic pharmacy. Am J Pharm Educ. 2012;76(10): 187. doi:10.5688/ajpe7610187

17. Townsend BK, Rosser VJ. Workload issues and measures of faculty productivity. Thought \& Action. 2007;23:1-14.

18. Glover ML, Armayor GM. Expectations and orientation activities of first-year pharmacy practice faculty. Am J Pharm Educ. 2004;68(4):Article 87. doi:10.5688/aj740467

19. Taylor CT, Berry TM. A pharmacy faculty academy to foster professional growth and long-term retention of junior faculty members. Am J Pharm Educ. 2008;72(2):32. doi:10.5688/ aj720232

20. Pfeiffenberger JA, Rhoney DH, Cutler SJ, et al. Perceptions of tenure and tenure reform in academic pharmacy. Am J Pharm Educ. 2014;78(4):75. doi:10.5688/ajpe78475 